\title{
Incremental Validity of the Satisfaction with Relationship Status Scale in Predicting Young Adults' Well-Being. What Does It Tell Us?
}

\author{
Katarzyna Adamczyk ${ }^{1}$ (D) \\ Published online: 13 August 2017 \\ (C) The Author(s) 2017. This article is an open access publication
}

\begin{abstract}
This study examined the incremental validity of the Satisfaction with Relationship Status Scale (ReSta; Lehmann et al. 2015) in comparison to the Relationship Assessment Scale (RAS; Hendrick 1988). The incremental validity of ReSta was assessed using a cross-sectional $(N=239)$ and longitudinal sample $(N=117)$ of Polish young adults aged 20 to 36. The results showed that ReSta, as opposed to RAS, predicted life satisfaction, emotional and psychological well-being, but it did not predict depressive symptoms, which were predicted by RAS. ReSta also significantly contributed to the higher accuracy of cross-validation of individuals to single and partnered groups when compared with RAS. The Satisfaction with Relationship Status Scale as an analog scale measuring satisfaction with relationship status provides meaningful information in the prediction of life satisfaction, and emotional and psychological well-being when compared with RAS, which in turn is the only significant predictor of depressive symptoms.
\end{abstract}

Keywords Incremental validity $\cdot$ Satisfaction with relationship status $\cdot$ Relationship satisfaction $\cdot$ Well-being · Young adults

\section{Introduction}

A considerable number of prior studies have demonstrated not only the existence of a link between marital and relationship status

Katarzyna Adamczyk

Katarzyna.Adamczyk@amu.edu.pl

1 Institute of Psychology, Adam Mickiewicz University, ul. A. Szamarzewskiego 89/AB, 60-568 Poznań, Poland and well-being, but also a link between marital and relationship satisfaction and well-being (e.g. Lyubomirsky et al. 2005). At the same time, the issue concerning the quality of marital and nonmarital relationships of individuals - with whom single individuals are compared in regard to happiness (life satisfaction) or any other outcomes - seems to be ignored in a number of prior studies (DePaulo and Morris 2005). One of the reasons explaining why relationship quality might have not been widely included in the analyses is the fact that relationship satisfaction can be reported only by partnered individuals. Therefore, single individuals obviously cannot be compared with partnered individuals in regard to relationship satisfaction (Levis et al. 2015). One of the attempts to overcome the lack of possibility of comparing single and partnered individuals in regard to relationship satisfaction is a recent study by Lehmann et al. (2015). Lehmann et al. (2015) developed the Satisfaction with Relationship Status Scale (ReSta). It is a generic tool measuring satisfaction with relationship status (i.e., having or not a partner). The ReSta was intended to be a first analog scale which could allow to perform comparisons between single and partnered adults in the domain of satisfaction with their current relationship status. Lehmann et al. (2015), who introduced a new construct of satisfaction with relationship status (status satisfaction), also demonstrated in their study that status satisfaction has a more explanatory value in predicting life satisfaction and psychological distress than marital status per se. Moreover, two recent studies by the present author replicated the results obtained by Lehmann et al. (2015), and revealed that status satisfaction is a better predictor of young adults' life satisfaction, emotional and psychological well-being, and depression (Adamczyk 2017a; Adamczyk 2017 b).

In addition, the current state of knowledge in the domain of psychosocial determinants of well-being has, however, also welcomed a recent study by Levis et al. (2015) who proposed a method integrating continuously measured marital satisfaction into models that could be investigated simultaneously among 
married and unmarried individuals. The procedure proposed by Levis et al. (2015) opened up the possibility of treating relationship satisfaction as a standard measure in comparisons between single and partnered individuals in the domain of well-being. The new procedure elaborated by Levis et al. (2015) also created the possibility of employing one of the most widely used scales to measure relationship satisfaction, that is the Relationship Assessment Scale (Hendrick 1988), in studies on single and partnered individuals. The Relationship Assessment Scale is an example of a brief tool designed for measuring global relationship satisfaction among individuals who are in different kinds of intimate relationships such as marital, cohabitating or dating relationships. As a result, RAS cannot provide data from single individuals who are not currently in a relationship and cannot report their experiences in regard to the issue of their satisfaction with a given relationship.

Considering on the one hand satisfaction with relationship status and a new scale measuring this construct (i.e. ReSta), and on the other hand the possibility of incorporating marital or relationship satisfaction in analyses including both single and partnered individuals as measured, for example, with the use of the Relationship Assessment Scale (RAS), we need to answer the question of which of these constructs may add more to the prediction of various outcomes, in particular such outcomes as well-being. On the theoretical level, the distinction between status satisfaction and relationship satisfaction as constructs seems to be clear since status satisfaction refers to the degree to which an individual is satisfied with his or her relationship status (Lehmann et al. 2015), whereas relationship satisfaction is generally understood as an individual's subjective global evaluation of his or her relationship (Graham et al. 2011). At the same time, even at an intuitive level, these constructs seem to be somehow related. Is status satisfaction a broader concept that reflects in its relationship satisfaction reported by partnered individuals? Which of these constructs could contribute more significantly to the prediction of young adults' well-being? These questions encouraged the present author to focus on incremental validity of the Satisfaction with Relationship Status Scale (ReSta) by Lehmann et al. (2015) as an analog scale designed to measure status satisfaction among single and partnered respondents.

\section{The Current Study}

The current study builds on prior research by Lehmann et al. (2015) and Levis et al. (2015), recognizing the importance of the inclusion of status satisfaction and relationship satisfaction in studies comparing single and partnered individuals in the domain of the broadly-defined well-being. The current investigation using a cross-sectional and longitudinal design (over a lag of two months) was intended to determine the incremental validity of ReSta as compared with one of the most commonly used measures of relationship satisfaction, namely the Relationship Assessment Scale (RAS; Hendrick 1988). The major purpose of the study was to assess the degree to which ReSta explains/predicts young adults' well-being relative to the RAS. The current study focuses only on the following selected dimensions of incremental validity (see Haynes and Lench 2003): (1) Incremental discriminant validity, that is, the degree to which ReSta would not exhibit high degree of shared variance with measures of dissimilar constructs (here with relationship satisfaction); (2) Incremental criterion validity, that is, the degree to which ReSta accounts for a higher proportion of variance in a criterion measure (i.e. well-being outcomes); (3) Incremental predictive validity, that is, the degree to which ReSta can account for a higher proportion of variance in well-being measured later (two months after the first assessment); and (4) Incremental discriminative validity, that is, the degree to which ReSta accurately identifies persons placed into groups on the basis of another measure (here on the basis on relationship status). In addition, the current study followed the procedure by Levis et al. (2015) who proposed how to incorporate marital satisfaction in the analysis including single and partnered individuals. As a result, this procedure allowed to compare ReSta and RAS.

The present study focuses on young adults since romantic relationships alongside work are important goals and developmental tasks in young adults' life (e.g. Rydz and Ramsz 2007) related to their well-being (e.g. Martikainen 2009). The current study also included as a criterion variables life satisfaction (as the most common indicator of subjective well-being; Díaz et al. 2015), emotional and psychological well-being, and depression as indicators of well-being in line with the recognized importance of considering mental health from the perspective of psychological distress as well as psychological well-being (Cierpiałkowska and Sęk 2015; Kaczmarek 2016; Trzebińska 2008). It is an important extension of the studies by Lehmann et al. (2015) and Levis et al. (2015), who did not investigate emotional and psychological well-being. Moreover, the current study also offers an excellent opportunity to verify the results obtained by Levis et al. (2015) since the authors in their study focused only on married, single, separated, divorced, and widowed women with systemic sclerosis (SSc) aged 18-83. The characteristics of the sample used in the study by Levis et al. (2015) create the need to verify their results in a non-clinical healthy sample consisting not only of female but also of male adults.

\section{Method}

\section{Participants and Procedure}

The study was carried out on a sample university students from different departments at Adam Mickiewicz University 
in Poznań in Poland and non-student individuals. Four hundred questionnaires were originally distributed. A total of 295 participants returned questionnaires (response rate $=\mathrm{a}$ $73.75 \%$ ). Of these, 56 participants were removed because of incomplete data, yielding a final sample of 239 participants. Participants were not offered any compensation for their participation in wave 1 and wave 2 .

Two hundred and thirty nine participants in wave 1 ranged in age from 20 to $36(M=23.01, S D=3.70)$. The sample was $52.70 \%$ female $(n=126)$ and $47.30 \%$ male $(n=113)$. In this sample, 159 individuals $(66.50 \%)$ were still students, whereas 80 respondents $(33.50 \%)$ were non-student individuals.

One hundred and twenty nine participants $(54.00 \%)$ indicated having a partner, whereas 110 participants $(46.00 \%)$ indicated being single. The average time of being in a relationship (duration of partnered status) was 32.68 months (2.72 years), with the standard deviation of 36.34 months (3.03 years). Among single individuals, the average time of remaining single (duration of single status) was 13.88 months (1.16 year), with the standard deviation of 19.63 months (1.64 year).

At a 2-month follow-up (T2), the sample consisted of 117 participants drawn from the sample used in wave 1. Of 239 eligible participants in wave 1,141 individuals declared their willingness to participate in wave 2 after a 2-month interval. Of these participants, 24 resigned from participation in the follow-up assessment. Therefore, the response rate for wave 2 was $48.95 \%$. The final sample in wave 2 consisted of 47 single respondents $(40.20 \%)$ and 70 respondents $(59.80 \%)$ in non-marital relationships. With regard to gender, women constituted $63.20 \%$ of the sample $(n=74)$, whereas men constituted $36.80 \%(n=43)$.

Comparison of participants of wave1 and wave 2 with those who participated only in wave 1 revealed no differences between those participants in regard to age, $F(1237)=2.83$, $p=.094$, and there were no differences in distribution of relationship status in wave 1 and wave $2, \mathrm{Phi}=.12$, $p=.075$. At the same time, significant differences were observed in regard to distribution of gender, Phi value $=.21$, $p=.001$, and distribution of education attainment, Phi value $=-.15, p=.02$, however, these Phi values indicated weak correlations. To be precise, there was a significant decrease in the percentage of male respondents who participated in wave 2 in comparison to wave 1 , and there was a significant increase of female respondents in wave 2 in comparison to wave 1. In regard to education attainment, there was a significant decrease in the percentage of respondents with high education in wave 2 in comparison to wave 1. Furthermore, no differences emerged to be significant in the domain of status satisfaction, $F(1237)=0.80, p=.371$, life satisfaction, $F(1237)=1.32$, $p=.252$, emotional well-being, $F(1237)=0.09, p=.761$, psychological well-being, $F(1237)=0.15, p=.697$, and depressive symptoms, $F(1237)=0.57, p=.450$.

\section{Measures}

Satisfaction with Relationship Status To measure satisfaction with relationship status the Satisfaction with Relationship Status Scale (ReSta; Lehmann et al. 2015) (Polish adaptation; Adamczyk 2017a) was used. The ReSta consists of five items rated on a on a four-point scale: 0 (not at all), 1 (a little), 2 (to quite some extent), 3 (to a great extent). In the present study, Guttman's $\lambda_{2}$ was found to be .94 in the first assessment and .97 in the second assessment.

Relationship Satisfaction To assess general relationship satisfaction the Relationship Assessment Scale (Hendrick 1988) (Polish adaptation - Monfort et al. 2014) was used. This questionnaire consisted of 7 items rated by respondents on a 5point scale ranging from 1 (not well) to 5 (very well). The internal consistency of the original scale was found to be $\alpha=.86$ (Hendrick 1988). In this sample, Guttman's $\lambda_{2}$ was determined to be .86 in the first assessment and .97 in the second assessment.

Life Satisfaction To asses one's individual satisfaction with life, the Satisfaction with Life Scale (SWLS; Diener et al. 1985) (Polish adaptation - Juczyński 2009) was employed. The SWLS is a 7-point Likert scale, ranging from strongly disagree (1) to strongly agree (7). The scale's internal consistency was determined to be $\alpha=.87$ (Diener et al. 1985). In the current study, Guttman's $\lambda_{2}$ was found to be .82 in the first assessment and .83 in the second assessment.

Emotional and Psychological Well-Being To assess emotional and psychological well-being the Mental Health Continuum - Short Form (MHC - SF; Keyes 2002) (Polish adaptation - Karaś et al. 2014) was used. This questionnaire includes 14 items assessing emotional, psychological, and social well-being. Participants rated questions about how they have been feeling during the past month using a scale ranging from 0 (never) to 5 (every day). In the current study, Guttman's $\lambda 2$ for emotional well-being was found to be .84 in the first assessment, and .86 in the second assessment, whereas for psychological well-being Guttman's $\lambda 2$ was found to be .85 in the first assessment and .86 in the second assessment.

Depression To measure depression, the Center for Epidemiological Studies Depression Scale (CES-D; Radloff 1977) (Polish adaptation - Kaniasty 2003) was used. It consists of 20 statements measuring the frequency of depressive symptoms which includes depressive affect (7 test items), absence of well-being (4 items), somatic symptoms ( 7 items), and interpersonal affect (2 items). Participants indicate the frequency of depressive symptoms in the past week using a 
four-point scale from 0 (rarely, or not at all) to 3 (most of the time or all the time).In the current study, Guttman's $\lambda 2$ was found to be .84 in the first assessment, and .85 in the second assessment.

\section{Results}

\section{Incremental Discriminant Validity}

In order to determine incremental discriminant validity, a zero-order correlation matrix including two predictors (i.e. status satisfaction and relationship satisfaction) and four criterion variables (i.e. life satisfaction, emotional well-being, psychological well-being, depressive symptoms) measured at wave 1 and wave 2 was examined (Table 1).

As Table 1 demonstrates, in wave 1 there was a strong positive correlation between status satisfaction and relationship satisfaction, which suggested that these measures might be redundant and that each of them would not significantly contribute to the increased variance in criterion variables. At the same time, in wave 2 no link between status satisfaction and relationship satisfaction was observed, which suggested that these measures could be independent.

Table 1 also provides data on the independent strength of associations between status satisfaction and relationship satisfaction and each of criterion variables, that is, well-being outcomes. Looking at the data shown in Table 1 with regard to the strength of significant correlations, it may be indicated that status satisfaction in wave 1 was more strongly correlated with life satisfaction and emotional well-being than relationship satisfaction, which in turn was more strongly correlated with psychological well-being and depressive symptoms. In turn, in wave 2, significant correlations were observed only between status satisfaction and life satisfaction, emotional and psychological well-being, and none of the correlations between relationship satisfaction and well-being outcomes emerged to be significant.

\section{Incremental Criterion and Predictive Validity}

The next step in the analytic strategy was aimed to determine whether adding a new measure (i.e. ReSta) to an existing measure of relationship satisfaction (i.e. RAS) would significantly contribute to the prediction of well-being outcomes, or whether a combination of these measures would strengthen this prediction (see Haynes and Lench 2003). Guided by these questions, a hierarchical regression analysis was performed separately for each of the criterion variables, that is for four well-being outcomes measured at T1 and T2. In the first step of the analysis, a comparison measure, RAS, was introduced, whereas in the second step ReSta was introduced. At the same time, the analysis was preceded by the transformation of relationship satisfaction into z-score as proposed by Levis et al. (2015). To be precise, since relationship satisfaction was examined only among partnered participants, standardized zscores from RAS were recorded for partnered individuals, whereas for single participants, a score of 0 was recorded. This way the interaction variable was constructed and introduced into the hierarchical regression analysis. Therefore, the regression coefficient of the interaction term reflected the changes in life satisfaction, emotional and psychological well-being, and depression scores associated with a 1 standard deviation change in total RAS scores. This transformation of relationship satisfaction into $\mathrm{z}$-score allowed for the inclusion of this variable in the analysis performed both on single and partnered individuals. Furthermore, this step of the analysis also included the determination of the difference in $R_{2}^{2}$ (i.e. the difference between $R^{2}{ }_{2}$ associated with ReSta and $R^{2}{ }_{1}$ associated with RAS) as an index of incremental validity of ReSta (see Table 2).

With respect to life satisfaction at $\mathrm{T} 1$ in the second step of the analysis, both z-score relationship satisfaction and status satisfaction significantly predicted life satisfaction; however, the standardized coefficient was higher for status satisfaction, indicating its stronger association with life satisfaction. At the same time, the percentage of variance in life satisfaction explained by both measures was $24.90 \%$, whereas the

Table 1 Synchronous zero-order correlations among major variables at T1 and T2

\begin{tabular}{|c|c|c|c|c|c|c|}
\hline Variables & 1 & 2 & 3 & 4 & 5 & 6 \\
\hline 1 Satisfaction with relationship status & - & $.49 * * *(.55 * * *)$ & $.68 * * *(.22)$ & $.38 * * *(.52 * * *)$ & $.32 * * *(.32 * * *)$ & $-.20 * *(-.15)$ \\
\hline 2 Life satisfaction & & - & $.41 * * *(.20)$ & $.21 * * *(.63 * * *)$ & $.52 * * *(.53 * * *)$ & $-.32 * * *(-.33 * * *)$ \\
\hline 3 Relationship satisfaction & & & - & $.10(.15)$ & $.34 * * *(.09)$ & $-.38 * * *(-.07)$ \\
\hline 4 Emotional well-being & & & & - & $.05(.82 * * *)$ & $.11\left(-.46^{* * *}\right)$ \\
\hline 5 Psychological well-being & & & & & - & $-.31 * * *(-.37 * * *)$ \\
\hline 6 Depression & & & & & & - \\
\hline
\end{tabular}

$N=239$ at $\mathrm{T} 1$ and $N=117$ at T2. Correlations in the brackets are provided for wave 2 . The correlations between relationship satisfaction and other variables were determined only in the group of partnered individuals. *** $p<.001$, two-tailed; $* * p<.01$, two-tailed 
Table 2 Hierarchical regression analysis predicting life satisfaction, emotional and psychological well-being, and depressive symptoms at T1and T2 using Z-score relationship Satisfaction at T1 (Step 1) and satisfaction with relationship status at T1 (Step 2)

\begin{tabular}{|c|c|c|c|c|}
\hline \multirow[b]{2}{*}{ Life satisfaction } & \multicolumn{2}{|l|}{ Step 1} & \multicolumn{2}{|l|}{ Step 2} \\
\hline & $\mathrm{B}(\mathrm{SE})$ & Beta & $\mathrm{B}(\mathrm{SE})$ & Beta \\
\hline Constant & 21.37 (0.33); $22.94(0.33)$ & & $16.05(0.78) ; 19.72(0.87)$ & \\
\hline Z-score relationship satisfaction & $2.08(0.45) ; 1.75(0.39)$ & $.29 * * * ; .39 * * *$ & $1.04(0.43) ; 1.14(0.40)$ & $.14 * ; .25 * *$ \\
\hline Satisfaction with relationship status & - & - & $0.52(0.07) ; 0.30(0.08)$ & $.44 * * *: .35 * * *$ \\
\hline$\Delta \mathrm{F}$ & $\begin{array}{l}F(1237)=21.42, p=.000 \\
F(1115)=20.32, p=.000\end{array}$ & & $\begin{array}{l}F(1236)=54.69 p=.000 \\
F(1114)=15.52 p=.000\end{array}$ & \\
\hline$\Delta \mathrm{R}^{2}$ & $.083 ; .150$ & & $.173 ; .102$ & \\
\hline $\mathrm{R}^{2}$ & $\mathrm{R}_{1:}^{2} .083 ; .150$ & & $\mathrm{R}_{2:}^{2} .249 ; .239$ & \\
\hline \multirow[t]{2}{*}{$\mathrm{R}_{\text {diff }}^{2}=\mathrm{R}_{2}^{2}-\mathrm{R}_{1}^{2}$} & $.166 ; .089$ & & & \\
\hline & Step 1 & & Step 2 & \\
\hline Emotional well-being & $\mathrm{B}(\mathrm{SE})$ & Beta & $\mathrm{B}(\mathrm{SE})$ & Beta \\
\hline Constant & $11.25(0.28) ; 9.41(0.19)$ & & $7.26(0.67) ; 7.52(0.50)$ & \\
\hline Z-score relationship satisfaction & $0.24(0.38) ; 0.10(0.22)$ & $.04 ; .39 * * *$ & $-0.54(0.37) ; 0.64(0.23)$ & $-.09 ; .25 * *$ \\
\hline Satisfaction with relationship status & - & - & $0.39(0.06) ; 0.18(0.04)$ & $.41 * * * ; .36^{* * *}$ \\
\hline$\Delta \mathrm{F}$ & $\begin{array}{l}F(1237)=0.41, p=.524 \\
F(1115)=20.04, p=.524\end{array}$ & & $\begin{array}{l}F(1236)=41.11, p=.000^{\prime} \\
F(1114)=16.56, p=.000\end{array}$ & \\
\hline$\Delta \mathrm{R}^{2}$ & $.002 ; .148$ & & $.148 ; .108$ & \\
\hline $\mathrm{R}^{2}$ & $\mathrm{R}_{1}^{2}: .002 ; .148:$ & & $\mathrm{R}_{2}^{2}: .143 ; .243$ & \\
\hline \multirow[t]{2}{*}{$\mathrm{R}_{\text {diff }}^{2}=\mathrm{R}_{2}^{2}-\mathrm{R}_{1}^{2}$} & $.141 ; .095$ & & & \\
\hline & Step 1 & & Step 2 & \\
\hline Psychological well-being & $\mathrm{B}(\mathrm{SE})$ & Beta & $\mathrm{B}(\mathrm{SE})$ & Beta \\
\hline Constant & $17.39(0.40) ; 17.73(0.36)$ & & 13.59 (1.01); $15.56(0.99)$ & \\
\hline Z-score relationship satisfaction & $2.06(0.54) ; 1.92(0.42)$ & $.24 * * * ; .39 * * *$ & $1.14(0.55) ; 11.51(0.45)$ & $.15^{*} ; .31 * *$ \\
\hline Satisfaction with relationship status & - & - & 0.37 (0.09); $0.20(0.09)$ & $.26 * * * ; .22 *$ \\
\hline$\Delta \mathrm{F}$ & $\begin{array}{l}F(1237)=14.52, p=.805 \\
F(1115)=20.59, p=.805\end{array}$ & & $\begin{array}{l}F(1236)=16.72, p=.326 \\
F(1114)=5.55, p=.020\end{array}$ & \\
\hline$\Delta \mathrm{R}^{2}$ & $.058 ; .152$ & & $.062 ; .039$ & \\
\hline $\mathrm{R}^{2}$ & $\mathrm{R}_{1}^{2}: .058 ; .152$ & & $\mathrm{R}_{2}^{2}: .113 ; .177$ & \\
\hline \multirow[t]{2}{*}{$\mathrm{R}_{\text {diff }}^{2}=\mathrm{R}_{2}^{2}-\mathrm{R}_{1}^{2}$} & $.055 ; .025$ & & & \\
\hline & Step 1 & & Step 2 & \\
\hline Depressive symptoms & $\mathrm{B}(\mathrm{SE})$ & Beta & $\mathrm{B}(\mathrm{SE})$ & Beta \\
\hline Constant & $17.11(0.48) ; 17.61(0.48)$ & & 19.07 (1.24); $16.88(1.34)$ & \\
\hline Z-score relationship satisfaction & $-3.02(0.65) ;-1.83(0.56)$ & $-.29 * * * ;-.29 * *$ & $-2.64(0.68) ;-1.97(0.61)$ & $-.25 * * * ;-.31 * * *$ \\
\hline Satisfaction with relationship status & - & - & $-0.19(0.11) ; 0.07(0.12)$ & $-.11 ; .06$ \\
\hline$\Delta \mathrm{F}$ & $\begin{array}{l}F(1.237)=21.66, p=.000 \\
F(1115)=10.58, p=.002\end{array}$ & & $\begin{array}{l}F(1236)=2.91, p=.089 \\
F(1114)=0.33, p=.565\end{array}$ & \\
\hline$\Delta \mathrm{R}^{2}$ & $.084 ; .084$ & & $.011 ; .003$ & \\
\hline $\mathrm{R}^{2}$ & $\mathrm{R}_{1}^{2}: .084 ; .084$ & & $\mathrm{R}_{2}^{2}: .087 ; .071$ & \\
\hline $\mathrm{R}_{\text {diff }}^{2}=\mathrm{R}_{2}^{2}-\mathrm{R}_{1}^{2}$ & $.003 ;-.013$ & & & \\
\hline
\end{tabular}

All data provided after the semicolon concern wave $2(N=117)$

$* * * p<.001 ; * * p<.01 ; * p<.05$

percentage of variance in life satisfaction explained by status satisfaction was $16.60 \%\left(\mathrm{R}^{2}\right.$ diff $\left.=.166\right)$.

With respect to emotional well-being at T1, in the second step of the analysis the only significant predictor of emotional well-being was status satisfaction, and the percentage of variance in life satisfaction explained by status satisfaction was $14.10 \%\left(\mathrm{R}_{\text {diff }}^{2}=.141\right)$.

With respect to psychological well-being at T1, in the final step of the analysis both z-score relationship satisfaction and status satisfaction significantly predicted psychological well- 
being; however, the standardized coefficient was higher for status satisfaction, indicating its stronger association with psychological well-being. The percentage of variance in psychological well-being explained by both measures was $11.30 \%$, whereas the percentage of variance in psychological wellbeing explained by status satisfaction was $5.50 \%\left(\mathrm{R}^{2}\right.$ diff $=$ .055).

Finally, in the domain of depressive symptoms at $\mathrm{T} 1$, in the second step of the analysis the only significant predictor of depressive symptoms was z-score relationship satisfaction, with higher relationship satisfaction related to lower depressive symptoms.

The data in Table 2 also provide results concerning the incremental predictive validity assessed by the use of longitudinal data, that is, the prediction of well-being outcomes at T2 from relationship satisfaction at T1 (Step 1) and status satisfaction at T1 (Step 2).

As Table 2 shows, with respect to life satisfaction at T2, similarly as in wave 1, both z-score relationship satisfaction and status satisfaction significantly predicted life satisfaction; however, the standardized coefficient was higher for status satisfaction, indicating its stronger association with life satisfaction. At the same time, the percentage of variance in life satisfaction explained by both measures was $23.90 \%$, whereas the percentage of variance in life satisfaction explained by status satisfaction was $8.90 \%\left(\mathrm{R}^{2}\right.$ diff $\left.=.089\right)$.

With respect to emotional well-being at $\mathrm{T} 2$, in the second step of the analysis both z-score relationship satisfaction and status satisfaction significantly predicted emotional wellbeing; however, the standardized coefficient was higher for status satisfaction, indicating its stronger association with emotional well-being. The percentage of variance in emotional well-being explained by both measures was $24.30 \%$, whereas the percentage of variance in emotional well-being explained by status satisfaction was $9.50 \%\left(\mathrm{R}^{2}\right.$ diff $\left.=.095\right)$.

In regard to psychological well-being at $\mathrm{T} 2$, in the second step of the analysis both z-score relationship satisfaction and status satisfaction significantly predicted psychological well-being; however, the standardized coefficient was higher for z-score relationship satisfaction. The percentage of variance in psychological well-being explained by both measures was $17.70 \%$, whereas the percentage of variance in psychological well-being explained by status satisfaction was $2.50 \%\left(\mathrm{R}^{2}\right.$ diff $\left.=.025\right)$.

Finally, in the domain of depressive symptoms at $\mathrm{T} 2$, in the second step of the analysis the only significant predictor of depressive symptoms was z-score relationship satisfaction, with higher relationship satisfaction related to lower depressive symptoms.

\section{Incremental Discriminative Validity}

In the final step of the analysis, incremental discriminative validity was investigated by the employment of a discriminant function analysis in order to compare the degree to which ReSta accurately identifies persons placed into single and partnered groups at $\mathrm{T} 1$ and $\mathrm{T} 2$ with the degree to which RAS accurately identifies persons placed into single and partnered groups at $\mathrm{T} 1$ and $\mathrm{T} 2$.

Using data from wave 1, the discriminant function analysis demonstrated that when ReSta was used, $79.50 \% \%$ of crossvalidated grouped cases were classified correctly, whereas when RAS was used, $53.60 \%$ of cross-validated grouped cases were classified correctly. In turn, when ReSta was used in wave 2, $91.50 \%$ of cross-validated grouped cases were classified correctly, whereas the use of RAS resulted in $59.80 \%$ of cross-validated grouped cases classified correctly.

\section{Discussion}

The current two-wave study drew upon two recent studies which contributed to new knowledge in the field on psychosocial determinants of well-being. Lehmann et al. (2015) introduced a new construct of satisfaction with relationship status and showed its greater explanatory value in predicting well-being beyond marital status. At the same time, a study by Levis et al. (2015) demonstrated how to incorporate in one's analysis continuously measured marital satisfaction without excluding single participants and how to determine the percentage of partnered individuals who would report the same or lower level of depression. These two studies touch upon the issue of incremental validity of the scale (ReSta) designed by Lehmann et al. (2015) to measure the construct of status satisfaction. Guided by this question, the current study intended to investigate the selected dimensions of incremental validity of ReSta in comparison to RAS when assessing general relationship satisfaction.

First, in the domain of incremental discriminant validity of ReSta, a zero-order correlation matrix including status satisfaction and relationship satisfaction as two predictors and four well-being outcomes as criterion variables measured at wave 1 and wave 2 was examined. Using cross-sectional data, it was determined that status satisfaction and relationship satisfaction are highly positively correlated; however, when using longitudinal data, the link did not emerge to be significant, pointing to the independence of these constructs. The same correlation matrix demonstrated stronger correlations between life satisfaction and emotional well-being than between relationship satisfaction and these outcomes in wave 1, and stronger correlations between relationship satisfaction with psychological well-being and depressive symptoms than between status satisfaction and these outcomes. At the same time, in wave 2 only status satisfaction was related to life satisfaction, emotional and psychological well-being, whereas relationship satisfaction was not related to any of the well-being outcomes. 
Second, incremental criterion validity was investigated when using cross-sectional data, as well as predictive validity was assessed using longitudinal data. In the domain of life satisfaction, cross-sectional data revealed that status satisfaction is a stronger predictor than relationship satisfaction, and the percentage of variance in life satisfaction explained by status satisfaction was $16.60 \%$. With respect to emotional well-being, cross-sectional data showed that status satisfaction is the only significant predictor, explaining $14.10 \%$ of variance in this outcome. In turn, in regard to psychological wellbeing at T1, z-score relationship satisfaction and status satisfaction were predictors, but status satisfaction was a stronger predictor than relationship satisfaction, although it explained merely $5.50 \%$ of the variance in this outcome. Finally, when it comes to depressive symptoms at T1, status satisfaction did not predict depressive symptoms, and only relationship satisfaction was a significant predictor. In turn, longitudinal data provided the following pattern of findings: with respect to life satisfaction, status satisfaction at $\mathrm{T} 1$ was a stronger predictor than relationship satisfaction at $\mathrm{T} 1$, although the percentage of variance in life satisfaction explained by status satisfaction $(8.90 \%)$ was lower than in wave 1 ; in regard to emotional well-being, status satisfaction was once again found to be a stronger predictor than relationship satisfaction, although it explained a much lower percentage of variance $(9.50 \%)$ than it did in wave 1 ; in the domain of psychological well-being at $\mathrm{T} 2$ - just like in the domain of psychological well-being at $\mathrm{T} 1$ - relationship satisfaction and status satisfaction significantly predicted this outcome, however, contrary to findings in wave 1 , relationship satisfaction was a stronger predictor than status satisfaction which explained merely $2.50 \%$ of the variance. Finally, in the domain of depressive symptoms at $\mathrm{T} 2$ - analogously to wave 1 - the only significant predictor of depressive symptoms was relationship satisfaction at $\mathrm{T} 1$.

In light of both the cross-sectional and longitudinal results, it may be concluded that generally status satisfaction is a stronger predictor of life satisfaction, emotional and psychological well-being than relationship satisfaction, and it significantly contributes to the explanation of variance in these outcomes. At the same time, it is clear that the only predictor of depressive symptoms is relationship satisfaction, and status satisfaction has to no degree contributed to the explained variance in this outcome. It appears that status satisfaction is more related to indicators of positive well-being than to indicators of psychological distress measured in terms of depressive symptoms. Moreover, it appears that relationship satisfaction is a better barometer of people's satisfaction with their relationships and that what is happens in their relationships is more related to depression than mere satisfaction with having a partner or not. Indeed, prior studies have shown that individuals in unhappy marriages or those who are dissatisfied with their partners have higher levels of depressive symptoms (St John and Montgomery 2009), and that a negative correlation between satisfaction in dating relationships and depressive symptoms exists (Whitton and Kuryluk 2012).

Therefore, it may be beneficial to consider using ReSta in research investigating indicators of positive well-being, whereas the use of RAS in studies investigating indicators of negative well-being should be considered. In addition, the assessment of the incremental discriminative validity of ReSta showed that ReSta also significantly contributed to higher accuracy of cross-validation of individuals to single and partnered groups than RAS does. At the same time, the present research calls for further studies which would help recognize and understand conditions in which ReSta and RAS may be used with benefits for predicting different outcomes. Additionally, since all measures are influenced by environmental circumstances (Perry 2001), they are - as Haynes and Lench (2003) described them - "conditional"; therefore, it is a one-off task that a researcher has to face when using their methodological skill set to "(...) determine under which conditions particular measures can provide valid and useful results" (Perry 2001, p. 406). Naturally, these conditional circumstances should be considered in relation to a concrete research aim formulated within a given study.

Drawing any conclusions concerning incremental validity of ReSta should be done with two major limitations taken into account. First, the sample size used in wave 2 was relatively small because of the attrition rate of $51.05 \%$ from wave 1 . As it was indicated, there was a significant decrease of male individuals and individuals with high education who participated in the second stage of the study in comparison to the first stage. It is reasonable to assume that this nonrandom dropout could significantly influence the obtained results. Larger longitudinal samples could certainly provide more robust results. Second, the current study compared ReSta with only one scale measuring relationship satisfaction. Future studies would benefit from comparing ReSta with other scales. Moreover, the current study leaves unanswered the question of whether the obtained results concerning relationship satisfaction could be replicated in regard to married individuals and marital satisfaction. Future studies could therefore extend the assessment of the incremental validity of ReSta by including measurements of marital satisfaction. Third, the samples in wave 1 and wave 2 represent developmental specificity of young adulthood in reference to such traits as the range of age groups, relational history (i.e., being never-married) and being childless together with the popularity of being a student and high education as an education attainment, and heterosexual orientation. Therefore, the findings cannot be generalized to individuals of other characteristics than those peculiar to the participants in the current study. Finally, the current investigation concentrated only on selected indicators of well-being. Future studies would benefit from including a much wider spectrum of these indicators and 
examining more indications of externalizing and internalizing problems (Cierpiałkowska 2007).

\section{Compliance with Ethical Standards}

Conflict of Interest The author declares that she has no conflict of interest.

Funding The author declares that she has no funding source to report.

Ethical Approval All procedures performed in studies involving human participants were in accordance with the ethical standards of the institutional and/or national research committee and with the 1964 Helsinki declaration and its later amendments or comparable ethical standards.

Informed Consent Informed consent was obtained from all participants included in the study.

Open Access This article is distributed under the terms of the Creative Commons Attribution 4.0 International License (http:// creativecommons.org/licenses/by/4.0/), which permits unrestricted use, distribution, and reproduction in any medium, provided you give appropriate credit to the original author(s) and the source, provide a link to the Creative Commons license, and indicate if changes were made.

\section{References}

Adamczyk, K. (2017a). Development and validation of a Polish-language version of the Satisfaction with Relationship Status Scale (ReSta). Current Psychology. doi: 10.1007/s12144-017-9585-9.

Adamczyk, K. (2017b). Going beyond relationship status: A crosssectionaland longitudinal investigation of the role of satisfaction with relationship statusin predicting Polish young adults' mental health. Journal of Social and Clinical Psychology, 36(4), 196-215. doi:10.1521/jscp.2017.36.4.265

Cierpiałkowska, L. (2007). Psychopatologia [psychopathology]. Warszawa: Wydawnictwo Naukowe SCHOLAR.

Cierpiałkowska, L., \& Sęk, H. (2015). Wyzwania dla psychologii klinicznej w XXI wieku [Challenges for clinical psychology in the XXI century]. Nauka, 2, 69-85.

DePaulo, B., \& Morris, W. (2005). Singles in society and science. Psychological Inquiry, 2-3, 57-83.

Díaz, D., Stavraki, M., Blanco, A., \& Gandarillas, B. (2015). The eudaimonic component of satisfaction with life and psychological well-being in Spanish cultures. Psicothema, 27(3), 247-253. doi:10. 7334/psicothema2015.5.

Diener, E., Emmons, R. A., Larsen, R. J., \& Griffin, S. (1985). The satisfaction with life scale. Journal of Personality Assessment, 49, 71-75.

Graham, J. M., Diebels, K. J., \& Barnow, Z. B. (2011). The reliability of relationship satisfaction: A reliability generalization meta-analysis. Journal of Family Psychology, 25(1), 39-48. doi:10.1037/ a0022441.

Haynes, S. N., \& Lench, H. C. (2003). Incremental validity of new clinical assessment measures. Psychological Assessment, 15(4), 456466. doi:10.1037/1040-3590.15.4.456.

Hendrick, S. S. (1988). A generic measure of relationship satisfaction. Journal of Marriage and the Family, 50, 93-98.

Juczyński, Z. (2009). Narzędzia pomiaru w promocji i psychologii zdrowia [Measurement instruments in the promotion and psychology of health]. Warszawa: Pracownia Testów Psychologicznych PTP.
Kaczmarek, Ł. D. (2016). Pozytywne interwencje psychologiczne. Dobrostan a zachowania intencjonalne [positive psychological interventions. Intentional activity and well-being]. Poznań: Wydawnictwo Zysk i S-ka.

Kaniasty, K. (2003). Kleska żywiołowa czy katastrofa społeczna? Psychospołeczne konsekwencje polskiej powodzi 1997 roku [Natural or social catastrophy? Psychosocial consequences of 1997 flood in Poland]. Gdańsk: Gdańskie Wydawnictwo Psychologiczne.

Karaś, D., Cieciuch, J., \& Keyes, C. L. M. (2014). The polish adaptation of the mental health continuum-short form (MHC-SF). Personality and Individual Differences, 69, 104-109. doi:10.1016/j.paid.2014. 05.011 .

Keyes, C. L. M. (2002). The mental health continuum: From languishing to flourishing in life. Journal of Health and Social Behavior, 43(2), 207-222.

Lehmann, V., Tuinman, M. A., Braeken, J., Vingerhoets, A. J. J. M., Sanderman, R., \& Hagedoorn, M. (2015). Satisfaction with relationship status: Development of a new scale and the role in predicting well-being. Journal of Happiness Studies, 16, 169-184. doi:10. 1007/s10902-014-9503-x.

Levis, B., Rice, D. B., Kwakkenbos, L., Steele, R. J., Hagedoorn, M., Hudson, M., Baron, B., Thombs, B. D., \& the Canadian Scleroderma Research Group. (2015). Using marital status and continuous marital satisfaction ratings to predict depressive symptoms in married and unmarried women with systemic sclerosis: A Canadian scleroderma research group study. Arthritis Care \& Research. doi:10.1002/acr.22802.

Lyubomirsky, S., King, L., \& Diener, E. (2005). The benefits of frequent positive affect: Does happiness lead to success? Psychological Bulletin, 131(6), 803-855. doi:10.1037/0033-2909.131.6.803.

Martikainen, L. (2009). The many faces of life satisfaction among Finnish young adults. Journal of Happinnes Studies, 10(6), 721-737. doi: 10.1007/s10902-008-9117-2.

Monfort, S. S., Kaczmarek, L. D., Kashdan, T. B., Drążkowski, D., Kosakowski, M., Guzik, P., Krauze, T., \& Gracanin, A. (2014). Capitalizing on the success of romantic partners: A laboratory investigation on subjective, facial, and physiological emotional processing. Personality and Individual Differences, 68, 149-153. doi: 10.1016/j.paid.2014.04.028

Perry, W. (2001). Incremental validity of the ego impairment index: A reexamination of Dawes (1999). Psychological Assessment, 13, 403 407. doi:10.1037//1040-3590.13.3.403

Radloff, L. S. (1977). The CES-D scale: A self-report depression scale for research in the general population. Applied Psychological Measurement, 1(3), 385-401. doi:10.1177/014662167700100306.

Rydz, E., \& Ramsz, J. (2007). Rozwój celów decyzji życiowo doniosłych w biegu życia człowieka. Empiryczne badanie młodzieży i osób dorosłych [Development of the goals of important life decisions in the human life cycle. Empirical research on adolescents and adults]. In E. Rydz, \& D. Musiał (Eds.), $Z$ zagadnien psychologii rozwoju czlowieka [From the issues in human development psychology] (pp. 217-234), Vol. 1. Lublin: Towarzystwo Naukowe Katolickiego Uniwersytetu Lubelskiego Jana Pawła II.

St John, P. D., \& Montgomery, P. R. (2009). Marital status, partner satisfaction, and depressive symptoms in older men and women. Canadian Journal of Psychiatry, 54(7), 487-492.

Trzebińska, E. (2008). Psychologia pozytywna [the positive psychology]. Warszawa: Wydawnictwa Naukowe i Profesjonalne.

Whitton, S. W., \& Kuryluk, A. D. (2012). Relationship satisfaction and depressive symptoms in emerging adults: Cross-sectional associations and moderating effects of relationship characteristics. Journal of Family Psychology, 26(2), 226-235. doi:10. 1037/a00. 